\title{
The Application of Risk Communication in Food Safety \\ Massimo Cecaro*
}

DVM, Specialist, Director of Accredited Training Centre in Agreement with University of Camerino, Italy

This article is the result of a review of the last research work related to food contact materials and the way institutions communicate their outcomes to the general public. Overall, it is hoped that this article raises the debate on risk communication, and has immediate relevance to its day-to-day practice. The Rapid Alert System for Food and Feed (RASFF) plays a key role in ensuring a high level of food safety for EU citizens. Through this system, food safety authorities in Europe are rapidly informed of serious risks found in relation to food or feed so that together they can react to health threats in a coordinated way [1]. Ensuring that what we eat is safe does not stop at testing the food itself. Everything that comes in contact with food as it is produced, packaged, transported, stored, prepared and consumed, also needs to be safe. This includes materials such as plastics, paper and board, metals, ceramics which are commonly used in manufacturing food packaging, and also kitchenware and cutlery and food processing equipment [2]. All Members of the RASFF (EU-27, European Commission, EFSA as well as Norway, Iceland, Liechtenstein and Switzerland) have a round-theclock service to ensure that urgent notifications are sent, received and responded to in the shortest time possible (RASFF Portal). Thanks to this alert system, many food safety risks have been averted before they could harm consumers [3]. According to the RASFF 2011 Annual Report's data Italy has confirmed its long tradition of control. It is true that our system has eradicated serious diseases, but it is also true that we have still important gaps in the practices of risk communication. These practices range from having no communication strategy at all to having communication with no strategy. Now a further step is needed, from "one medicine approach" to "one communication approach". Health information institutions could potentially have a major influence on future communication strategies if they create a sort of standard to inform all stakeholders of the outcome of their evaluations. Information to the consumer is one of the main concern of the alert system, but in fact there is still a wide divergence between scientific and lay perceptions of risk, especially on a local basis. As highlighted by the WHO since after the BSE crisis, we have to stress the need for better "communication of risk" and find a way to express the conclusions once the scientific and policy deliberations have been completed. Now a further step is needed, from "one medicine approach" to "one communication approach". Are we well-equipped to face this challenge?

\section{References}

1. Rasff Portal

2. $\mathrm{IHCP}$.

3. European Commission "Keeping dangerous food off the shelves : Commission publishes annual report on EU's Rapid Alert System for Food and Feed" $\mathrm{IP} / 13 / 520$
*Corresponding author: Massimo Cecaro, DVM, Specialist, Director of Accredited Training Centre in Agreement with University of Camerino, Italy, E-mail: massimo@cecaro.com

Received October 11, 2013; Accepted October 15, 2013; Published October 23 2013

Citation: Cecaro M (2013) The Application of Risk Communication in Food Safety. J Mass Communicat Journalism S1: 003. doi:10.4172/2165-7912.S1-003

Copyright: (c) 2013 Cecaro M. This is an open-access article distributed under the terms of the Creative Commons Attribution License, which permits unrestricted use, distribution, and reproduction in any medium, provided the original author and source are credited. 